KREATIF : Jurnal Ilmiah Prodi Manajemen Universitas Pamulang, Vol. 8, No.2, Desember 2020

KREATIF

\title{
PENGARUH KOMPETENSI, KOMITMEN ORGANISASI, DAN PENGEMBANGAN KARIR TERHADAP KINERJA KARYAWAN PADA PT BANK CIMB NIAGA, TBK CABANG KABUPATEN TEMANGGUNG
}

\author{
Lidya Pricilla ${ }^{1}$ dan Irma Sari Octaviani ${ }^{2}$ \\ ${ }^{1-2}$ Program Studi Manajemen Universitas Pamulang. \\ email: dosen02479@unpam.ac.id
}

\begin{abstract}
ABSTRAK
Tujuan diadakannya penelitian ini adalah untuk mengetahui dan menganalisis pengaruh kompetensi, komitmen organisasi dan pengembangan karir terhadap kinerja karyawan pada PT. Bank Cimb Niaga, Tbk Cabang Kabupaten Temanggung.

Metode yang digunakan dalam penelitian ini menggunakan metode Asosiatif. Sampel yang digunakan dalam penelitian ini sebanyak 60 responden. Teknik pengumpulan data dalam penelitian ini menggunakan kuesioner. Adapun teknik analisis data dalam penelitian ini menggunakan regresi linier berganda.

Hasil penelitian menunjukan bahwa: Semakin baik tingkat kompetensi yang dimiliki oleh karyawan akan membuat peningkatan kinerja karyawan. Pengaruh dari variabel tersebut adalah positif signifikan atau $(0,007<0,05)$. Semakin baik tingkat komitmen yang dimiliki oleh para karyawan akan membuat peningkatan kinerja karyawan. Pengaruh dari variabel tersebut adalah positif signifikan atau $(0,005<0,05)$. Semakin baik pengembangan karir akan membuat peningkatan kinerja karyawan. Pengaruh dari variabel tersebut adalah positif signifikan atau $(0,049<0,05)$. Semakin baik tingkat kompetensi yang dimiliki oleh karyawan, tingginya tingkat komitmen, serta pengembangan karir yang baik akan membuat peningkatan kinerja karyawan. Pengaruh dari variabel tersebut adalah positif signifikan atau $(0,000<0,01)$.
\end{abstract}

Kata Kunci :Kompetensi, Komitmen Organisasi, Pengembangan Karir, Kinerja Karyawan.

\section{ABSTRACT}

The purpose of this research is to find out and analyze the effect of competence, organizational commitment and career development on employee performance at PT. Bank Cimb Niaga, Tbk Temanggung Regency Branch.

The method used in this study uses the Associative method. The sample used in this study were 60 respondents. Data collection techniques in this study used a questionnaire. The data analysis techniques in this study multiple linear regression.

The results showed that: The better level of competency possessed by employees will make an increase in employee performance. The effect of these variables is significant or $(0.007$ <0.05). The better the level of commitment owned by the employees will make an increase in employee performance. The effect of these variables is significant or 10.005 $<0.05)$. The better career development will increase employee performance. The effect of these variables is significant or $(0.049<0.05)$. The better the level of competency 
KREATIF : Jurnal Ilmiah Prodi Manajemen Universitas Pamulang, Vol. 8, No.2, Desember 2020

possessed by employees, the high level of commitment, and good career development will increase employee performance. The effect of these variables is significant or $(0,000$ $<0.01$ ).

Keywords: Competence, Organizational Commitment, Career Development, Employee Performance

\section{PENDAHULUAN}

\section{A. Latar Belakang Masalah}

Saat ini persaingan antar lembaga Bank sangat ketat, mereka berlomba-lomba untuk memberikan pelayanan yang berkualitas terhadap nasabah dan calon nasabah baru mulai dari cleaning service, keamanan, kasir dan pegawai lainnya. Untuk itu peran karyawan yang handal dan kompeten sangat diperlukan guna menunjang kegiatan perusahaan untuk memberikan pelayanan yang berkualitas agar para nasabah menjadi loyal terhadap perusahaan dan tidak beralih keperusahaan lainnya.

Data yang penulis temukan pada perusahaan ini menunjukan adanya suatu permasalahan tentang adanya penurunan kinerja karyawan yang dilihat dari bagaimana para karyawan memberikan pelayanan kepada nasabah. Banyaknya komplenan-komplenan yang masuk juga turut mempengaruhi penilaian kinerja, baik dari sisi penyelesaian masalah, tingkat keagresifan dalam melayani, tingkat antrian dan kesopanan dalam bekerja. Data yang penulis temui dapat di temukan pada tabel berikut ini:

Tabel 1. Hasil Penilaian Kinerja Karyawan PT. Bank Cimb Niaga, Tbk, Cabang Kabupaten Temanggung

\begin{tabular}{|l|c|c|c|c|c|c|}
\hline \multirow{2}{*}{$\begin{array}{c}\text { Penilaian } \\
\text { Kinerja }\end{array}$} & \multicolumn{2}{|c|}{ Tahun 2017 } & \multicolumn{2}{c|}{ Tahun 2018 } & \multicolumn{2}{c|}{ Tahun 2019 } \\
\cline { 2 - 7 } & $\begin{array}{c}\text { Jumlah } \\
\text { Orang }\end{array}$ & Persentase & $\begin{array}{c}\text { Jumlah } \\
\text { Orang }\end{array}$ & Persentase & $\begin{array}{c}\text { Jumlah } \\
\text { Orang }\end{array}$ & Persentase \\
\hline Baik Sekali & 30 & $50 \%$ & 25 & $42 \%$ & 18 & $30 \%$ \\
\hline Baik & 10 & $17 \%$ & 12 & $20 \%$ & 9 & $15 \%$ \\
\hline Cukup & 9 & $15 \%$ & 8 & $13 \%$ & 13 & $22 \%$ \\
\hline Kurang & 11 & $18 \%$ & 15 & $25 \%$ & 20 & $33 \%$ \\
\hline Total & 60 & $100 \%$ & 60 & $100 \%$ & 60 & $100 \%$ \\
\hline
\end{tabular}

Sumber: Bagian SDM PT. Bank Cimb Niaga, Tbk, Cabang Kabupaten Temanggung, (2020)

Terlihat dari Tabel 1 bahwa pada tahun 2018 dengan kategori kinerja sangat baik diperoleh 25 orang atau 42\%, dibandingkan tahun 2017 bahkan 30 orang atau 50\%, namun pada tahun 2019 terjadi penurunan lagi yaitu bertambah 18 orang atau 30\%. . Berdasarkan tabel tersebut dapat disimpulkan bahwa pencapaian PT. Bank Cimb Niaga, Tbk Cabang Kabupaten Temanggung cenderung menurun.

Banyak hal yang dapat mempengaruhi penyebab menurunnya penilaian kinerja tersebut, bisa disebabkan adanya pengaruh dari dalam bisa juga disebabkan pengaruh dari luar. Pengaruh dari luar bisa disebabkan oleh tingginya persaingan antar lembaga Bank di daerah sekitar. Adapun pengaruh dari dalam disebabkan oleh kompetensi, komitmen organisasi dan pengembangan karier.

Kompetensi seorang pegawai mutlak diperlukan dalam menunjang kegiatan pelayanan terutama kepada nasabah, karena dengan adanya kompetensi yang unggul dan mampu menguasai sistem kerja yang baik akan berdampak sangat baik dalam proses pelayanan yang diberikan. Bandingkan jika seorang pegawai yang belum faham betul tentang sistem kerja dan pemahaman produk maka akan membuat pelayanan menjadi terganggu dan akan membuat image perusahaan menjadi buruk dimata nasabah. 
KREATIF : Jurnal Ilmiah Prodi Manajemen Universitas Pamulang, Vol. 8, No.2, Desember 2020

Sama halnya dengan komitmen organisasi yang menjadi penentu keberhasilan perusahaan dalam mencapai tujuan dan visi perusahaan. Banyaknya anggota yang tidak memiliki hasrat untuk memajukan perusahaan tentu akan berdampak negatif, biasanya karyawan tersebut cenderung bermalas-malasan dalam bekerja, kurang taat dalam bekerja, sering tidak masuk kerja dan loyalitas yang menurun. Komitmen yang kuat dalam diri yang sudah tertanam dalam sanubari karyawan pasti akan membawa suatu aura positif dalam memberikan kinerja yang optimal dan tentu akan membawa suatu dampak positif. Karena mereka yang memiliki komitmen kuat pasti akan bekerja lebih giat, loyalitas tinggi dan memiliki motivasi yang kuat dalam bekerja.

Seorang pegawai mampu bekerja dengan maksimal jika ada suatu dorongan yang bisa membawa mereka untuk dapat bekerja lebih baik, yaitu adanya kepastian karir. Kepastian karir pada diri pegawai akan membuat mereka merasa aman, tenang, tidak banyak pikiran. Karena jika karir pegawai yang dibatasi oleh perusahaan akan membuat mereka menjadi kurang termotivasi dalam bekerja dan cenderung menjadi malas.

\section{B. Rumusan Masalah}

1. Bagaimana pengaruh kompetensi terhadap kinerja karyawan?

2. Bgaimana pengaruh komitmen karyawan terhadap kinerja karyawan?

3. Bagaimana pengaruh pengemban karir terhadap kinerja karyawan?

4. Bagaimana pengaruh kompetensi, komitmen dan pengembangan karir terhadap kinerja karyawan?

\section{TINJAUAN PUSTAKA}

\section{A. Kompetensi}

Emron (2016: 143), "kompetensi adalah sifat yang mendasari seseorang yang menghasilkan pekerjaan yang efektif dan / atau kinerja yang luar biasa". Sedangkan menurut Malayu (2016: 17), "kompetensi adalah kemampuan individu untuk melakukan pekerjaan dengan baik dan memiliki kelebihan berdasarkan pada masalah yang berkaitan dengan pengetahuan, keterampilan, dan sikap". Menurut Kandula (2013:6), dimensidimensi dan indikator kompetensi adalah mencakup pengetahuan, keterampilan, motif, sifat, dan citra diri.

\section{B. Komitmen OrganisasI}

Kasvāns (2015:125), "Komitmen suatu organisasi dapat dilihat dari ketekunan karyawan dalam organisasi tempatnya bekerja dan keinginan untuk bekerja untuk / atas nama organisasi serta kesempatan untuk mempertahankan keanggotaannya". Moorhead \& Griffin (2013: 73), sementara itu, "Komitmen organisasi adalah sikap yang mencerminkan sejauh mana seseorang mengetahui dan melekat pada organisasinya".

Menurut Kaswan (2015:126) komitmen organisasi terdiri atas tiga dimensi yaitu Komitmen Afektif, Komitmen Kelanjutan, dan Komitmen Normatif.

\section{Pengembangan Karir}

Menurut Widodo (2015:53), “pengembangan karir adalah rangkaian kegiatan sepanjang hidup yang berkontribusi pada eksplorasi, penguatan, kesuksesan dan pemenuhan karir seseorang”. Menurut Prabu (2015:77), "pengembangan karir merupakan kegiatan ketenagakerjaan yang membantu karyawan merencanakan karir masa depannya di perusahaan agar perusahaan dan karyawan terkait dapat berkembang secara optimal”.

Menurut Rivai (2015:278) dimensi dan indikator yang mempengaruhi pengembangan karier adalah prestasi kerja, kesetiaan organisasi, mentor dan sponsor, dukungan dari bawahan, serta kesempatan untuk bertumbuh. 
KREATIF : Jurnal Ilmiah Prodi Manajemen Universitas Pamulang, Vol. 8, No.2, Desember 2020

\section{Kinerja Karyawan}

Menurut Robert dan Bakala (2016: 153), "kinerja adalah kontribusi karyawan terhadap tujuan pekerjaan atau unit kerjanya dan perusahaan / organisasi sebagai akibat dari perilaku dan penerapan keterampilan, kemampuan, dan pengetahuan". Rivai dan Sagala (2016: 269-270) berpendapat bahwa "kinerja adalah perilaku nyata yang ditunjukkan setiap orang sebagai kinerja kerja yang diciptakan karyawan sesuai dengan peran mereka dalam organisasi."

Dimensi dan Indikator kinerja pegawai menurut Mangkunegara (2015:67) adalah, kualitas kerja, kuantitas kerja, tanggung jawab, kerjasama dan inisiatif.

\section{E. Kerangka Berfikir}

Menurut Sugiyono (2017: 128), "Rencana pemikiran yang baik secara teoritis akan menjelaskan keterkaitan antar variabel yang diteliti, sehingga pengaruh antara variabel bebas dan variabel terikat perlu dijelaskan secara teoritis".

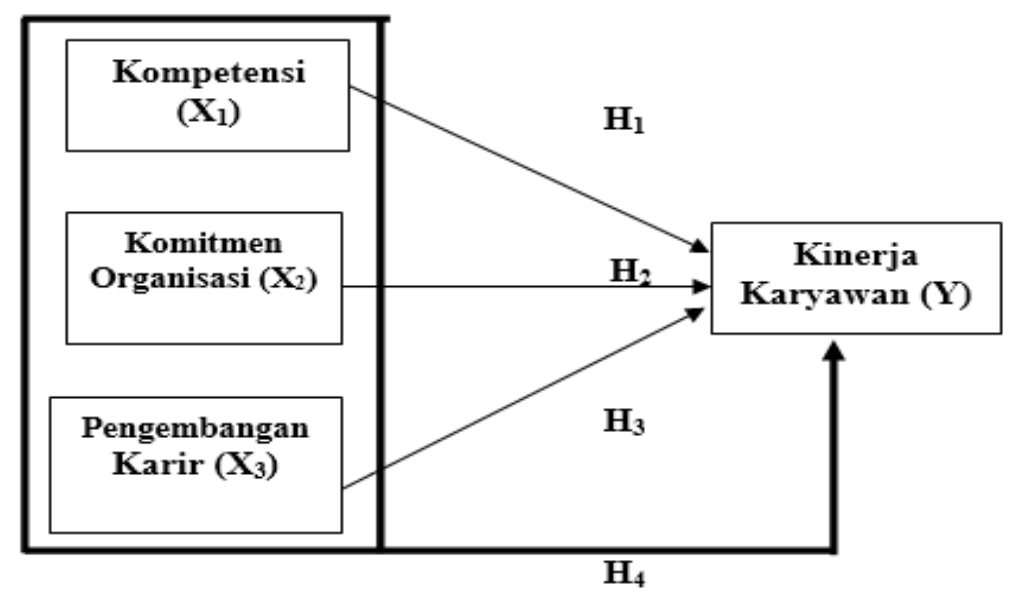

Gambar 1. Kerangka Berfikir

\section{F. Hipotesis}

Menurut Sugiyono (2017: 63), "Hipotesis adalah tanggapan sementara terhadap rumusan masalah penelitian, dimana rumusan masalah tersebut dinyatakan dalam bentuk pernyataan". Hipotesis penelitian ini adalah sebagai berikut:

$\mathrm{H}_{1}=$ "Diduga kompetensi berpengaruh positif dan signifikan terhadap kinerja karyawan".

$\mathrm{H}_{2}=$ "Diduga komitmen organisasi berpengaruh positif dan signifikan terhadap kinerja karyawan".

$\mathrm{H}_{3}=$ "Diduga pengembangan karir berpengaruh positif dan signifikan terhadap kinerja karyawan".

$\mathrm{H}_{4}=$ "Diduga kompetensi, komitmen organisasi dan pengembangan karir secara simultan berpengaruh positif dan signifikan terhadap kinerja karyawan”.

\section{METODE PENELITIAN}

Metode yang digunakan adalah metode asosiatif, menurut Sugiyono (2017:44), "Tujuan dari studi asosiasi adalah untuk mengetahui pengaruh atau hubungan antara dua variabel lainnya". Semua karyawan PT berpartisipasi dalam penelitian ini. Bank Cimb Niaga, Tbk cabang Kabupaten Temanggung memiliki 60 karyawan. 60 responden adalah sampel sampel jenuh.

\section{A. Uji Instrument}


KREATIF : Jurnal Ilmiah Prodi Manajemen Universitas Pamulang, Vol. 8, No.2, Desember 2020

1. Validitas

Menurut Sugiyono (2017:267), "validitas adalah tingkat ketepatan antara data yang dihasilkan pada subjek penelitian dan data yang dapat dilaporkan oleh peneliti".

2. Reliabilitas

Menurut Ghazali (2016:78), "Reliabilitas adalah tingkat reliabilitas suatu angket, angket reliabel adalah angket yang apabila diujikan ulang pada kelompok yang sama akan memperoleh data yang sama, dengan asumsi responden tidak mengalami perubahan psikologis".

B. Uji Asumsi Klasik

1. Uji Normalitas

Menurut Sugiyono (2017: 239), "uji normalitas digunakan untuk menilai normalitas dari variabel yang diteliti, terlepas dari apakah datanya berdiseminasi normal atau tidak".

2. Uji Multikolinearitas

Menurut Ghazali (2016:82), “tujuan uji linieritas multikolor adalah untuk menguji apakah ditemukan korelasi antar variabel bebas (independen) dalam model regresi”.

3. Uji Heteroskedastisitas

Menurut Ghazali (2016: 83), “tujuan pengujian ini adalah untuk menguji apakah terdapat varian yang tidak merata dalam model regresi antara sisa-sisa pengamatan satu dengan yang lain".

\section{Teknik Analisis Data}

1. Regresi Linier Berganda

Menurut Sugiyono (2017: 277), "regresi linier berganda mengasumsikan keadaan variabel dependen (naik dan turun) ketika dua atau lebih variabel independen dimanipulasi sebagai prediktor (kenaikan dan penurunan nilai)." Dengan demikian, jika jumlah variabel bebas minimal dua maka dilakukan analisis multi regresi.

$\mathbf{Y}=\mathbf{a}+\boldsymbol{\beta}_{1} \mathbf{X}_{1}+\boldsymbol{\beta}_{2} \mathbf{X}_{2}+\boldsymbol{\beta}_{3} \mathbf{X}_{3}$

2. Koefisien Determinasi

Menurut Ghazali (2016: 97), "koefisien determinasi $\left(\mathrm{R}^{2}\right)$ pada dasarnya mengukur sejauh mana suatu model mampu menjelaskan variasi dalam suatu variabel terikat".

$$
\mathrm{KD}=\mathbf{r}^{2} \times 100 \%
$$

Dimana:

$\mathrm{KD}=$ Koefisien determinasi

$\mathrm{r}^{2} \quad$ Kuadrat Koefisien Korelasi

3. Uji t

Menurut Ghazali (2016: 84), “Tujuan dari uji t-statistik adalah untuk mengetahui ada tidaknya pengaruh parsial dari masing-masing variabel independen terhadap variabel dependen".

$$
\mathbf{t}=\frac{\mathbf{r} \sqrt{\mathbf{n}-\mathbf{2}}}{\sqrt{\mathbf{1 - \mathbf { r } ^ { 2 }}}}
$$

4. Uji F 
KREATIF : Jurnal Ilmiah Prodi Manajemen Universitas Pamulang, Vol. 8, No.2, Desember 2020

Menurut Ghazali (2016: 98), "Uji statistik F pada dasarnya menunjukkan apakah semua variabel independen yang dimasukkan dalam model memiliki pengaruh yang sama terhadap variabel dependen".

$$
F=\frac{r^{2} / K}{\left(1-r^{2}\right)(n-k-1)}
$$

\section{HASIL DAN PEMBAHASAN}

A. Uji Validitas dan Reliabilitas

Tabel 2. Hasil Uji Validitas

\begin{tabular}{|c|c|c|c|c|c|c|}
\hline Pernyataan & rhitumg $\mathrm{X}_{1}$ & rhitumg $\mathrm{X}_{2}$ & rhitumg $_{3}$ & rhitumg $\mathrm{Y}$ & rtabel $_{1}$ & Keputusan \\
\hline P1 & 0,588 & 0,502 & 0,870 & 0,939 & 0,254 & Valid \\
\hline P2 & 0,670 & 0,778 & 0,861 & 0,968 & 0,254 & Valid \\
\hline P3 & 0,709 & 0,705 & 0,876 & 0,879 & 0,254 & Valid \\
\hline P4 & 0,558 & 0,790 & 0,910 & 0,929 & 0,254 & Valid \\
\hline P5 & 0,730 & 0,837 & 0,936 & 0,910 & 0,254 & Valid \\
\hline P6 & 0,857 & 0,827 & 0,928 & 0,939 & 0,254 & Valid \\
\hline P7 & 0,752 & 0,849 & 0,929 & 0,528 & 0,254 & Valid \\
\hline P8 & 0,781 & 0,767 & 0,909 & 0,511 & 0,254 & Valid \\
\hline P9 & 0,787 & 0,784 & 0,929 & 0,791 & 0,254 & Valid \\
\hline P10 & 0,693 & 0,762 & 0,761 & 0,901 & 0,254 & Valid \\
\hline
\end{tabular}

Sumber: Data Primer diolah dengan SPSS 25, (2020)

Dari 40 pernyataan disebar kepada karyawan terlihat bahwa seluruhnya memiliki angka tinggi dari $r_{\text {tabel }}(0,254)$ dengan semua item pernyataan valid.

Tabel 3 Hasil Uji Reliabilitas

\begin{tabular}{|l|c|c|}
\hline \multicolumn{1}{|c|}{ Variabel } & Cronbach Alpha & Keputusan \\
\hline Kompetensi $\left(\mathrm{X}_{1}\right)$ & 0,887 & Sangat Reliabel \\
\hline Komitmen Organisasi $\left(\mathrm{X}_{2}\right)$ & 0,919 & Sangat Reliabel \\
\hline Pengembangan Karir $\left(\mathrm{X}_{3}\right)$ & 0,969 & Sangat Reliabel \\
\hline Kinerja Karyawan $(\mathrm{Y})$ & 0,946 & Sangat Reliabel \\
\hline
\end{tabular}

Sumber: Hasil Olahan Data SPSS 25, (2020)

Tabel 3 diatas menunjukan kriteria sudah terpenuhi artinya 40 pernyataan yang disebar kepada karyawan adalah reliabel.

\section{B. Uji Asumsi Klasik}

\section{Uji Normalitas}


KREATIF : Jurnal Ilmiah Prodi Manajemen Universitas Pamulang, Vol. 8, No.2, Desember 2020

Tabel 4. One-Sample Kolmogorov-Smirnov Test

\begin{tabular}{|c|c|c|}
\hline & Unstandardized Residual \\
\hline \multicolumn{2}{|l|}{$\mathrm{N}$} & 60 \\
\hline \multirow{2}{*}{$\begin{array}{l}\text { Normal } \\
\text { Parameter }{ }^{\mathrm{a}, \mathrm{b}}\end{array}$} & Mean & 0,0000000 \\
\hline & Std. Deviation & 4,78449680 \\
\hline \multirow{3}{*}{$\begin{array}{l}\text { Most Extreme } \\
\text { Differences }\end{array}$} & Absolute & 0,086 \\
\hline & Positive & 0,068 \\
\hline & Negative & $-0,086$ \\
\hline \multicolumn{2}{|l|}{ Test Statistic } & 0,086 \\
\hline \multicolumn{2}{|c|}{ Asymp. Sig. (2-tailed) } & $200^{c, d}$ \\
\hline \multicolumn{3}{|c|}{ a. Test distribution is Normal. } \\
\hline \multicolumn{3}{|c|}{ b. Calculated from data. } \\
\hline \multicolumn{3}{|c|}{ G. Lilliefors Significance Correction. } \\
\hline \multicolumn{3}{|c|}{ d. This is a lower bound of the true significance. } \\
\hline \multicolumn{3}{|c|}{ Sumber: Data diolah dengan SPSS 25, (2020) } \\
\hline
\end{tabular}

Angka sebesar 0,200 > 5\% standar kritis yang merupakan asumsi normalitas sudah dapat dipenuhi.

\section{Uji Multikolinearitas}

Tabel 5. Uji Multikolinearitas

\begin{tabular}{|l|c|c|}
\hline \multirow{2}{*}{ Model } & \multicolumn{2}{|c|}{ Collinearity Statistics } \\
\cline { 2 - 3 } & Tolerance & VIF \\
\hline Kompetensi & 0,749 & 1,335 \\
\hline Komitmen Organisasi & 0,785 & 1,273 \\
\hline Pengembangan Kariri & 0,675 & 1,482 \\
\hline
\end{tabular}

a. Dependent Variable: Keputusan Pembelian

Sumber: Hasil Olahan Data SPSS 25, (2020)

Pada tabel 5 menunjukan tidak terdapat adanya suatu gejala-gejala yang memungkinkan adanya multikolinearitas karena $\mathrm{VIF}<10$ dan toleransi $>0,10$.

\section{Uji Heteroskedastisitas}

Tabel 6. Uji Heterokesdastisitas

\begin{tabular}{|c|c|c|c|c|c|c|}
\hline & \multirow[t]{2}{*}{ Model } & \multicolumn{2}{|c|}{$\begin{array}{c}\text { Unstandardized } \\
\text { Coefficients }\end{array}$} & \multirow{2}{*}{$\begin{array}{l}\text { Standardized } \\
\text { Coefficients } \\
\text { Beta }\end{array}$} & \multirow[t]{2}{*}{$\mathrm{t}$} & \multirow[t]{2}{*}{ Sig. } \\
\hline & & B & Std. Error & & & \\
\hline \multirow[t]{4}{*}{1} & (Constant) & 4,104 & 2,138 & & 1,920 & 0,060 \\
\hline & Kompetensi & $-0,051$ & 0,044 & $-0,176$ & $-1,157$ & 0,252 \\
\hline & Komitmen & 0,039 & 0,052 & 0,111 & 0,751 & 0,456 \\
\hline & Pengembangan Karir & $-0,004$ & 0,033 & $-0,019$ & $-0,117$ & 0,908 \\
\hline
\end{tabular}

a. Dependent Variable: AbsRes

Sumber: Hasil Olahan Data SPSS 25, (2020)

Berdasarkan Tabel 6. Keseluruhan variabel signifikansi > 5\% menyebabkan heteroskedastisitas tidak terjadi. 
KREATIF : Jurnal Ilmiah Prodi Manajemen Universitas Pamulang, Vol. 8, No.2, Desember 2020

\section{Regresi Linier Berganda}

Tabel 7. Regresi Linier Berganda

\begin{tabular}{|c|c|c|c|c|c|c|}
\hline & & \multicolumn{2}{|c|}{$\begin{array}{c}\text { Unstandardized } \\
\text { Coefficients }\end{array}$} & \multirow{2}{*}{$\begin{array}{l}\text { Standardized } \\
\text { Coefficients } \\
\text { Beta }\end{array}$} & \multirow[b]{2}{*}{$\mathrm{t}$} & \multirow[b]{2}{*}{ Sig. } \\
\hline \multicolumn{2}{|c|}{ Model } & $\mathrm{B}$ & Std. Error & & & \\
\hline \multirow[t]{4}{*}{1} & (Constant) & 19,657 & 3,507 & & 5,606 & 0,000 \\
\hline & Kompetensi & 0,201 & 0,072 & 0,316 & 2,802 & 0,007 \\
\hline & Komitmen & 0,248 & 0,085 & 0,321 & 2,923 & 0,005 \\
\hline & Pengembangan Karir & 0,110 & 0,055 & 0,239 & 2,014 & 0,049 \\
\hline
\end{tabular}

a. Dependent Variable: Kinerja Karyawan

Sumber: Hasil Olahan Data SPSS 25, (2020)

$Y=19,657+0,201 X_{1}+0,248 X_{2}+0,110 X_{3}$

1. Nilai constant sebesar 19,657 artinya seluruh variabel independen tidak mengalami peningkatan sama sekali yang berarti kinerja karyawan tetap 19,657.

2. Kompetensi memperoleh nilai regresi $0,201 \mathrm{X}_{1}$ berarti bahwa pengaruh yang searah yang artinya semakin baik kompetensi karyawan dalam melayani pelanggan baik maka akan membuat peningkatan kinerja karyawan 0,201.

3. Komitmen memperoleh nilai regresi $0,248 \mathrm{X}_{2}$ berarti bahwa pengaruh yang searah yang artinya jika komitmen karyawan untuk dapat memberikan pekerjaan sebaik mungkin maka akan membuat peningkatan kinerja karyawan 0,248.

4. Pengembangan karir memperoleh nilai regresi $0,110 \mathrm{X}_{3}$ berarti bahwa pengaruh yang searah yang artinya jika pengembangan karier karyawan sesuai dengan penilaian yang adil maka akan membuat peningkatan kinerja karyawan 0,110.

\section{Koefisien Determinasi}

Tabel 8. Koefisien Determinasi

\begin{tabular}{|c|c|c|c|c|}
\hline Model & R & R Square & Adjusted R Square & $\begin{array}{c}\text { Std. Error of the } \\
\text { Estimate }\end{array}$ \\
\hline 1 &, $684^{\mathrm{a}}$ & 0,468 & 0,440 & 4,91098 \\
\hline
\end{tabular}

a. Predictors: (Constant), Pengembangan Karir, Komitmen, Kompetensi

Sumber: Hasil Olahan Data SPSS 25, (2020)

Hasil ini menunjukkan kontribusi (dampak) sebesar 46,8\% yang dihasilkan dari ketiga variabel bebas terhadap kinerja karyawann adapun 53,2\% adalah penyebab dari faktor-faktor lain.

\section{Uji Hipotesis Parsial}

a) Hasil pengujian regresi pada tabel 7 angka angka sig $(0,007<0,05)$ menunjukan diterimanya $\mathrm{H}_{\mathrm{a} 1}$ dan ditolaknya $\mathrm{H}_{\mathrm{o} 1}$ yang berarti kompetensi berpengaruh terhadap kinerja karyawan secara parsial.

b) Hasil pengujian regresi pada tabel 7 angka angka sig $(0,005<0,05)$ menunjukan diterimanya $\mathrm{H}_{\mathrm{a} 2}$ dan ditolaknya $\mathrm{H}_{\mathrm{o} 2}$ yang berarti komitmen berpengaruh terhadap kinerja karyawan secara parsial.

c) Hasil pengujian regresi pada tabel 7 angka angka sig $(0,049<0,05)$ menunjukan diterimanya $\mathrm{H}_{\mathrm{a}}$ dan ditolaknya $\mathrm{H}_{03}$ yang berarti pengembagan karir berpengaruh terhadap kinerja karyawan secara parsial. 
KREATIF : Jurnal Ilmiah Prodi Manajemen Universitas Pamulang, Vol. 8, No.2, Desember 2020

\section{Uji Hipotesis Simultan}

Tabel 9. Uji F hitung

\begin{tabular}{|l|l|r|r|r|r|r|}
\hline \multicolumn{2}{|l|}{ Model } & $\begin{array}{c}\text { Sum of } \\
\text { Squares }\end{array}$ & \multicolumn{1}{c|}{ df } & $\begin{array}{c}\text { Mean } \\
\text { Square }\end{array}$ & F & Sig. \\
\hline \multirow{2}{*}{1} & Regression & 1189,140 & 3 & 396,380 & 16,435 &, $000^{\mathrm{b}}$ \\
\cline { 2 - 7 } & Residual & 1350,593 & 56 & 24,118 & & \\
\cline { 2 - 7 } & Total & 2539,733 & 59 & & & \\
\hline
\end{tabular}

a. Dependent Variable: Kinerja Karyawan

b. Predictors: (Constant), Pengembangan Karir, Komitmen, Kompetensi

Sumber: Hasil Olahan Data SPSS 25, (2020)

Angka pada probabilitas lebih kecil dan lebih rendah dari 0,01 atau $(0,000<0,01)$, yang berarti diterimanya $\mathrm{H}_{\mathrm{a} 4}$ dan ditolaknya $\mathrm{H}_{04}$ menunjukan kinerja karyawan dipengaruhi secara simultan oleh adanya variabel kompetensi, komitmen, dan pengembangan karir.

\section{KESIMPULAN DAN SARAN}

\section{A. Kesimpulan}

1) Semakin baik tingkat kompetensi yang dimiliki oleh karyawan akan membuat peningkatan kinerja karyawan yang tinggi. Pengaruh dari variabel tersebut adalah positif signifikan atau $(0,007<0,05)$.

2) Semakin baik tingkat komitmen karyawan akan membuat peningkatan kinerja karyawan yang tinggi. Pengaruh dari variabel tersebut adalah positif signifikan atau $(0,005<0,05)$.

3) Semakin baik pengembangan karir akan membuat peningkatan kinerja karyawan yang tinggi. Pengaruh dari variabel tersebut adalah positif signifikan atau $(0,049<$ $0,05)$.

4) Semakin baik tingkat kompetensi yang dimiliki oleh karyawan, tingginya tingkat komitmen, serta pengembangan karir yang baik akan membuat peningkatan kinerja karyawan yang tinggi. Pengaruh dari variabel tersebut adalah positif signifikan atau $(0,000<0,01)$.

\section{B. Saran}

1) Untuk meningkatkan keterampilan karyawan dalam bekerja, perusahaan harus memberikan program pelatihan bagi karyawan, dan ini dilakukan sebulan sekali.

2) Sebaiknya manajemen harus memberikan penghargaan kepada karyawan yang berprestasi dalam keunggulan, sehingga karyawan memiliki komitmen yang kuat untuk mengembangkan perusahaan, hal ini dilakukan sedemikian rupa agar karyawan yang berkinerja baik tidak meninggalkan perusahaan.

3) Pelatihan yang diberikan harus mengarah pada perkembangan yang lebih besar dan harus selalu diperbarui. Penyediaan materi pelatihan harus sejalan dengan perkembangan teknologi guna mendukung kinerja pegawai.

4) Untuk mempertahankan kinerja yang sudah dicapai, maka sebaiknya mempertahankan dan meningkatkan kualitas program pelatihan yang ada dan kinerja karyawan PT. Bank Cimb Niaga, Tbk di Kabupaten Temanggung dapat menjadi lebih baik lagi.

\section{DAFTAR PUSTAKA}


KREATIF : Jurnal Ilmiah Prodi Manajemen Universitas Pamulang, Vol. 8, No.2, Desember 2020

Edison, dkk. (2016). "Manajemen Sumber Daya Manusia". Cetakan ke-1. Bandung : Alfabeta.

Hasibuan, Malayu. (2016). "Manajemen Sumber Daya Manusia". EPT. Edisi Revisi. Jakarta: $\quad$ Penerbit PT Bumi Aksara.

Kaswan. (2015). "Sikap Kerja: Dari Teori dan Implementasi Sampai Bukti”. Bandung: Alfabeta.

Mangkunegara, A. P. (2015). "Manajemen Sumber Daya Manusia Perusahaan”. Bandung: PT Remaja Rosdakarya.

Moorhead \& Griffin. (2013). "Perilaku Organisasi”. Jakarta: Salemba Empat.

Rivai, Veithzal dan Sagala Jauvani Ella. (2016). "Manajemen Sumber Daya Manusia Untuk Perusahaan Dari Teori Ke Praktik". Jakarta: PT. Rajawali Pers.

Robert \& Bacal. (2016). "Performance Management". Jakarta: Gramedia Pustaka Utama.

Sugiyono. (2017). "Metode Penelitian Manajemen". Bandung: CV Alvabeta.

Widodo, Eko Suparno. (2015). "Manajemen Pengembangan Sumber Daya Manusia". Yogyakarta: Pustaka Pelajar. 